\title{
Role of NT-proBNP in detection of myocardial damage in childhood leukemia survivors treated with and without anthracyclines
}

Beata Mladosievicova ${ }^{*}$, Dagmar Urbanova ${ }^{1}$, Eva Radvanska $^{2}$, Peter Slavkovsky $^{1}$ and Iveta Simkova ${ }^{3}$

\begin{abstract}
Background: Exposure to anthracyclines (ANT) during childhood represents a high risk for development of late cardiotoxicity. Cardiotoxicity is usually detected only when clinical symptoms or progressive cardiac dysfunction have already occurred. Early detection of cardiotoxicity may lead to better therapeutic outcome. N-terminal probrain natriuretic peptide (NTproBNP) has been hypothesized to reflect increased left ventricular wall stress before development of echocardiographic abnormalities. The aim of this study was to detect cardiac abnormalities using plasma NTproBNP and echocardiography in asymptomatic childhood leukemia survivors treated with or without cardiotoxic anthracycline therapy.
\end{abstract}

Methods: Serum levels of NTproBNP were determined in 69 asymptomatic survivors of childhood leukemia treated with or without anthracyclines and in 44 apparently healthy controls. The survivors were divided into two treatment groups: 36 patients after chemotherapy containing anthracyclines (ANT) and 33 patients after chemotherapy without anthracyclines (nonANT). Levels of NTproBNP were measured by using the Elecsys 2010 immunoassay analyzer (Roche Diagnostics). Echocardiography using M-mode, two-dimensional and Doppler measurements were performed on the same day as blood samples were obtained for NTproBNP analysis in survivors.

Results: Serum levels of NTproBNP were significantly higher in the ANT group than in controls (median 51.52 vs $17.37 \mathrm{pg} / \mathrm{ml} ; \mathrm{p}=0.0026)$. Survivors exposed to ANT had significantly increased levels of NTproBNP compared with patients treated without ANT (median $51.52 \mathrm{vs} 12.24 \mathrm{pg} / \mathrm{ml} ; \mathrm{p}=0.0002$ ). Female exposed and unexposed survivors had significantly higher NTproBNP levels than males. Four of the 36 survivors (11\%) treated with ANT and two of the 33 patients (6\%) not exposed to ANT had abnormal NTproBNP levels. Although no patient had echocardiographic abnormalities, significant differences were found in values of left ventricular ejection fraction (LVEF) and deceleration time (DT) between survivors treated with or without anthracyclines.

Conclusions: Higher levels of NTproBNP detected in childhood leukemia survivors after low anthracycline cumulative doses might reflect an initial stage of ANT cardiotoxicity before the development of echocardiographic abnormalities. Although the current studies support NTproBNP as one of the best available biochemical markers of late anthracycline cardiotoxicity, a possible strategy toward further improvement and combination with other cardiac biomarkers and novel echocardiographic methods should be explored in additional studies.

Keywords: Cardiotoxicity, Anthracyclines, Natriuretic peptides, Echocardiography, Survivors

\footnotetext{
* Correspondence: beata.mladosievicova@fmed.uniba.sk

'Institute of Pathological Physiology, School of Medicine, Comenius

University, Sasinkova 4, 811 08, Bratislava, Slovak Republic

Full list of author information is available at the end of the article
} 


\section{Introduction}

Childhood cancer survivors exposed to anthracyclines are at increased risk for premature cardiac morbidity and mortality [1-8]. For 30 years after cancer treatment, survivors are 15 times more likely to experience heart failure than the general population [8]. Cardiac effects of the therapy for acute leukemia in childhood are of particular concern. In more than half of the exposed survivors, cardiotoxic treatment was found to be associated with left ventricular (LV) subclinical structural and functional abnormalities, which can progress to clinically manifested heart failure [9].

Diagnosis of cardiac dysfunction and heart failure after anticancer therapy is based on medical history, physical examination and is further confirmed by other tests, mainly echocardiography. Nevertheless, clinical misdiagnosis is common, particularly in early stages of heart failure. Current monitoring techniques, such as MUGA (Multi Gated Acquisition Scan) or echocardiography, have substantial limitations and detect LV dysfunction only after it had occurred. Cardiotoxicity is usually diagnosed only upon manifestation of clinical signs and symptoms or progressive cardiac dysfunction. Thus new diagnostic tests are required to confirm ventricular dysfunction induced by anticancer therapy .

Novel echocardiographic techniques are promising in evaluating the presence of myocardial structural alterations and subtle myocardial dysfunction induced by anticancer therapy, yet they are not used in routine clinical practice.

Although new cardiac imaging techniques, such as quantitative assessment of ventricular function through measurement of myocardial strain and strain rate can more precisely assess heart structure and function during and early after cardiotoxic therapy, it remains to be proven whether they have the ability to detect early treatment-induced cardiac injury in long-term cancer survivors several years after completion of malignancy therapy. Morevover, the definition of reference range of ventricular strain and strain rate values in normal adults and description of the variability among systems and observers are debatable [10,11].

Early and accurate diagnosis of ventricular dysfunction in asymptomatic cardiac patients may permit a prompt onset of therapy of subclinical cardiotoxicity before the development of life-threatening complications.

This study aims to detect cardiac abnormalities using plasma $\mathrm{N}$-terminal pro brain natriuretic peptide (NTproBNP) and echocardiography in asymptomatic childhood leukemia survivors treated with or without cardiotoxic anthracyclines (ANT).

\section{Methods}

Childhood acute leukemia survivors without any cardiac symptoms were consecutively recruited in the out- patient clinic of the National Cancer Institute, Bratislava, Slovak Republic, from January 2006 to October 2010. A total of 69 survivors of acute leukemia were involved, aged 17-31 years, whose chemotherapy completion dated back for at least 5 years. They had been treated between 1985 and 2005 in a single center - at the Children's University Hospital, Bratislava. Survivors were divided into two treatment groups: 36 patients who had received chemotherapy containing cardiotoxic anthracyclines (ANT) and 33 patients after chemotherapy without anthracyclines (nonANT) (Table 1). Only one patient was treated with ANT in combination with mediastinal radiation.

The survivors who had received the cardioprotective agent dexrazoxane were excluded. Furthermore, patients with renal insufficiency, liver dysfunction, abnormal blood pressure, abnormal body mass index and those who were on any current medication, were excluded to avoid possible effects on NTproBNP values.

To establish NTproBNP reference values, we selected a control group of 44 subjects (aged 20-28 years, 50\% women) without any known cardiovascular risk factors and no clinical evidence of heart, lung, renal, liver or systemic disease. A blood sample was drawn and stored under the same conditions as in the patients. In this study, our normal values of NTproBNP were different for females $(<105 \mathrm{pg} / \mathrm{mL})$ and males $(<75 \mathrm{pg} / \mathrm{mL})$ (below 97.5th percentile from controls).

All participants or their guardians gave their written informed consent. The study was approved by the Ethics Committee of the National Cancer Institute and the

Table 1 Characteristics of the study participants

\begin{tabular}{|c|c|c|c|}
\hline & $\begin{array}{l}\text { ANTgroup } \\
(\mathrm{N}=36)\end{array}$ & $\begin{array}{l}\text { NonANT group } \\
(\mathrm{N}=33)\end{array}$ & $\begin{array}{l}\text { Control } \\
\text { group } \\
(\mathrm{N}=44)\end{array}$ \\
\hline Sex $M / F$ & $19 / 17$ & $16 / 17$ & $22 / 22$ \\
\hline Diagnosis & ALL (33) & ALL (33) & \\
\hline (No. of pts) & AML (3) & & \\
\hline Age at diagnosis, yrs & $8(1-17)$ & $5(2-10)$ & \\
\hline \multicolumn{4}{|l|}{ Median (range) } \\
\hline $\begin{array}{l}\text { Time since completion } \\
\text { of therapy, yrs } \\
\text { Median (range) }\end{array}$ & $11(5-22)$ & $15(6-25)$ & \\
\hline $\begin{array}{l}\text { Age at time of the } \\
\text { study, yrs }\end{array}$ & $22(18-31)$ & $23(17-31)$ & $23(20-28)$ \\
\hline \multicolumn{4}{|l|}{ Median (range) } \\
\hline \multirow[t]{4}{*}{ Chemotherapy } & Doxorubicin & $\begin{array}{l}\text { Cyclophosphamide } \\
\text { Vincristine }\end{array}$ & \\
\hline & Daunorubicin & L-Asparaginase & \\
\hline & Epirubicin & Methotrexate & \\
\hline & & 6-Mercaptopurine & \\
\hline
\end{tabular}

Values are presented as median (range).

ALL, acute lymphoblastic leukemia; AML, acute myeloblastic leukemia. 
Faculty of Medicine, Comenius University in Bratislava, Slovak Republic.

All patients were examined by a general cardiologist. The blood samples for immunochemical analysis were obtained at the same day as the echocardiographic measurement was performed.

\section{Biochemical analysis}

EDTA-anticoagulated blood ( $5 \mathrm{ml}$ ) was collected by venous puncture. Fasting was not a prerequisite before sampling. The whole blood was centrifuged for 10 minutes (3500 rpm) within $2 \mathrm{~h}$ after sampling. Centrifuged plasma $(500 \mu \mathrm{L})$ was aliquoted to labeled eppendorf tubes before freezing and stored at $-20^{\circ} \mathrm{C}$ until assayed.

The cardiac biomarker NTproBNP was measured at the Clinical Biochemistry Department, National Cardiovascular Institute, Bratislava, Slovak Republic, within two months after collection. Hemolyzed samples were excluded. Venous blood samples were obtained in the morning and serum concentrations of biomarkers were measured by electrochemiluminescence immunoassay on Elecsys analyzer (Roche Diagnostics). The detection limit for the NTproBNP assay is $5 \mathrm{pg} / \mathrm{mL}$.

We compared the NTproBNP levels between the studied groups exposed and unexposed to ANT and our ageand sex-matched control group.

\section{Echocardiography}

Echocardiography using a GE VIVID 7 machine (GE Ultrasound Europe) was performed in all patients included in the study. Assessment was done by one experienced cardiologist who was unaware of the participants' treatment status and the NTproBNP value.

Standard techniques were used to obtain M-mode, two-dimensional and Doppler (color, pulse, continuous, tissue) echocardiograms.

Left ventricular (LV) end-diastolic diameter (LVEDD), LV end-systolic diameter (LVESD) and left atrium dimension were measured using standard M-mode methods from parasternal LV long axis images. LV ejection fraction (EF) was calculated by Teichholz formula (Mmode) as well as by the Simpson method from apical view (two-dimensional echocardiography). Systolic LV dysfunction was defined as EF less than or equal to $50 \%$.

Quantification of metric and functional echocardiographic parameters was based on the recommendations of the American Society of Echocardiography's Guidelines and Standards Committee and the Chamber Quantification Writing Group [12].

Pulsed Doppler traces of the mitral valve inflow were used to extract the ratio of peak early to peak late flow velocities (E/A), E-wave deceleration time (DT), LV isovolumetric relaxation time (IVRT) and were assessed as standard parameters of LV diastolic function. Diastolic
LV dysfunction was defined as E/A inversion and DT above $220 \mathrm{~ms}$ on the transmitral Doppler curve (impaired relaxation).

The tissue Doppler imaging (TDI) of the mitral annulus from apical four-chamber view provided additional parameters reflecting the global systolic and diastolic function of the LV. Early diastolic velocity (Ea) of the mitral annulus was considered a good indicator of LV myocardial relaxation and diastolic function, and so was the ratio of early diastolic myocardial velocity $(\mathrm{Em})$ and late diastolic myocardial velocity (Am).

Peak systolic velocity at myocardial segments (Sm) was used to assess systolic function. The ratio of early diastolic LV inflow velocity (E) to Ea of the medial mitral annulus (E/Ea) was used for estimation of the LV filling pressure [13].

\section{Statistical analysis}

Continuous variables (echocardiographic parameters) are presented as mean \pm SD (standard deviation) and the cardiac biomarker NTproBNP as median and interquartile range. Comparisons between continuous or categorical variables were performed using the Student t-test, Mann-Whitney and Wilcoxon test. Correlations were evaluated with Spearman correlation coefficient. A p-value less than 0.05 was considered statistically significant.

\section{Results}

Serum levels of NTproBNP were significantly higher in survivors treated with anthracylines than in controls (median 51.52 vs $17.37 \mathrm{pg} / \mathrm{mL} ; \mathrm{p}=0.0026)$. Survivors exposed to ANT had significantly increased levels of NTproBNP compared with survivors treated without ANT (median 51.52 vs $12.24 \mathrm{pg} / \mathrm{mL}$; $\mathrm{p}=0.0002$ ). Levels of NTproBNP in survivors not exposed to ANT compared with controls were not significantly different (median 12.24 vs $17.37 \mathrm{pg} / \mathrm{mL}$; $\mathrm{p}=0.051$ ) (Figure 1).

Abnormal NTproBNP levels were detected in 4/36 (11\%) survivors in the ANT group and in $2 / 33$ (6\%) in the nonANT group.

Women exposed to anthracyclines had significantly higher values of NTproBNP than exposed men: median (25th-75th percentiles): 82.6 (51.5-99.1) vs 38.1 (22.2-53.7) pg/mL; p $=0.0031$.

Unexposed female survivors had significantly higher values of NTproBNP than unexposed male survivors: median (25th-75th percentiles): 44.6 (21.6-83.2) vs 17.6 (12.5-24.7) $\mathrm{pg} / \mathrm{mL} ; \mathrm{p}=0.0039$ (Table 2).

No significant differences in NTproBNP values were found between females and males from control group: median (25th-75th percentiles): 28.8 (17.1-44.5) vs 17.2 (10.3-33.9) $\mathrm{pg} / \mathrm{mL} ; \mathrm{p}=0.12$. 


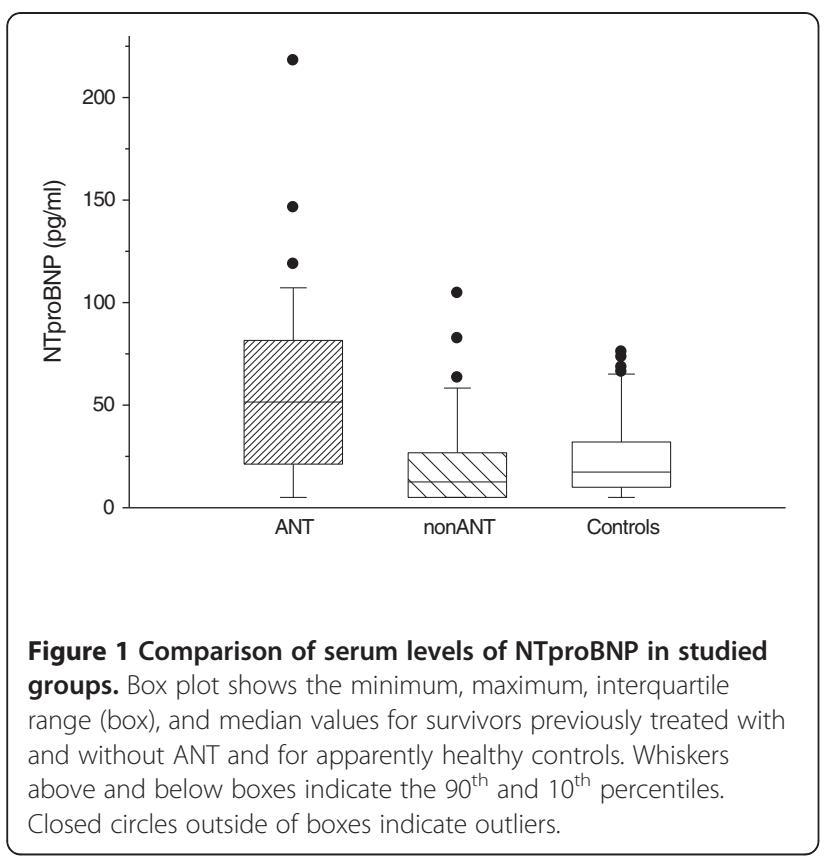

Although no patient had echocardiographic abnormalities, significant differences were found in values of left ventricular ejection fraction (LVEF) and deceleration time (DT) between survivors exposed and not exposed to anthracyclines (Table 3).

NT proBNP values positively correlated with ANT dose (rho $=0.51, \mathrm{p}=0.0028$ ) but failed to correlate with LVEF (rho $=0.1488, \mathrm{p}=0.4245)$ and DT (rho $=0.1506, \mathrm{p}$ $=0.4269$ ).

\section{Discussion}

Measurement of natriuretic peptides (NP) is routinely used in diagnosis and management of cardiac dysfunction and heart failure [14]. Natriuretic peptides are produced within the heart and released into the circulation in response to increased wall tension, reflecting increased volume or pressure overload. Under pathologic stimuli, the prohormone BNP is synthesized,

Table 2 Gender-specific values for NTproBNP (pg/mL) by exposure to anthracyclines

\begin{tabular}{llll}
\hline & Females & Males & P-value \\
\hline Exposed & $\mathrm{N}=17$ & $\mathrm{~N}=19$ & \\
Median (25th-75th) & $82.6(51.5-99.1)$ & $38.1(22.2-53.7)$ & 0.0031 \\
\hline Unexposed & $\mathrm{N}=17$ & $\mathrm{~N}=16$ & \\
Median (25th-75th) & $44.6(21.6-83.2)$ & $17.6(12.5-24.7)$ & 0.0039 \\
\hline Controls & $\mathrm{N}=22$ & $\mathrm{~N}=22$ & \\
Median (25th-75th) & $28.8(17.1-44.5)$ & $17.2(10.3-33.9)$ & 0.12 \\
\hline
\end{tabular}

NTproBNP, N-terminal pro-brain natriuretic peptide. Results are expressed as median and quartiles.
Table 3 Echocardiographic parameters in the groups of survivors

\begin{tabular}{lccl}
\hline & NonANT group & ANTgroup & P value \\
\hline LVEF (\%) (Simpson) & $69.8 \pm 6.4$ & $66.4 \pm 4.5$ & $<0.05$ \\
Sm & $0.12 \pm 0.03$ & $0.16 \pm 0.16$ & NS \\
E/A & $1.8 \pm 0.5$ & $1.7 \pm 0.5$ & NS \\
DT (ms) & $195.3 \pm 32.9$ & $219.6 \pm 55.5$ & $<0.05$ \\
IVRT (ms) & $72.2 \pm 7.9$ & $74.1 \pm 7.9$ & NS \\
E/Ea & $6.5 \pm 1.4$ & $6.2 \pm 1.6$ & NS \\
Em/Am & $2.3 \pm 0.7$ & $2.1 \pm 0.6$ & NS \\
LVEDD (mm) & $45.7 \pm 4.9$ & $46.2 \pm 4.2$ & NS \\
LVESD (mm) & $28.1 \pm 6.4$ & $29.3 \pm 3.5$ & NS \\
LA (mm) & $32.4 \pm 3.9$ & $32.5 \pm 4.2$ & NS \\
RV (mm) & $26.1 \pm 3.2$ & $26.1 \pm 3.4$ & NS \\
\hline
\end{tabular}

Values are presented as mean \pm SD.

cleaved to BNP, releasing N-terminal fragment of the brain natriuretic peptide (NTproBNP). Many studies reported that NTproBNP concentrations increased with the severity of ventricular dysfunction and heart failure $[13,15,16,17]$.

NTproBNP is a promising candidate marker for the exclusion and detection of ventricular dysfunction after potentially cardiotoxic anticancer therapy [2,13,15-28]. Although the role of NTproBNP in the early detection of myocardial damage after anticancer therapy has been evaluated in several studies, the focus was mainly on levels of this biomarker during or only several months after chemotherapy $[13,18-20,22,23]$. So far only a limited number of studies have investigated the levels of NTproBNP as a marker of late cardiotoxicity occurring several years after completion of chemotherapy in cancer survivors [2,26-28]. In our recent study, we have found significantly elevated NTproBNP levels in childhood leukemia survivors at a median of 10.5 years after completion of anthracycline therapy in comparison with apparently healthy controls [27].

In the present study, this finding was extended to show NTproBNP levels not only in survivors after ANT therapy but also in patients unexposed to anthracyclines. The NTproBNP values in unexposed survivors were found to be comparable to those determined in the control group. According to our information, only one other study reported recently NTproBNP levels in survivors who received ANT compared with patients not receiving these agents [28]. These authors confirmed higher NTproBNP values in the ANT group than in controls yet they found that not only exposed but also unexposed survivors had elevated NTproBNP. They suggest that a chronic inflammatory process may be a predisposing factor of cardiomyopathy in cancer survivors unexposed to anthracyclines. Systemic inflammation in cancer 
survivors has been of particular concern in recent pathophysiological studies. The discrepancy between the study of Lipshultz et al. [28] and the presented study might be explained by differences in characteristics of the study participants (cancer treatment history, gender, age, body mass index and other risk factors).

In the present study, the detection of cardiotoxicity was performed in childhood leukemia survivors after a low cumulative ANT dose (with median $221 \mathrm{mg} / \mathrm{m}^{2}$ ). So far only few studies have been published that assessed cardiotoxicity after such ANT doses [26,27]. We found significantly higher serum levels of NTproBNP in patients exposed to anthracyclines than in unexposed survivors and controls. These results might reflect anthracycline-induced cardiac abnormalities (such as loss of cardiomyocytes and damage of the remaining cardiomyocytes and other myocardial cells).

The sex-related differences in NTproBNP levels in our patients are consistent with other authors demonstrating that female survivors are more vulnerable to anticancer cardiotoxic and non- cardiotoxic treatments [28].

In the study we found that $11 \%$ survivors treated with ANT (with median cumulative dose $221 \mathrm{mg} / \mathrm{m}^{2}$ ) and $6 \%$ of patients previously unexposed to anthracyclines had abnormal NTproBNP levels. In the study of Mavinkurve-Groothius et al. [26], abnormal levels of NTproBNP were detected in $13 \%$ of 122 asymptomatic survivors of childhood cancer who had received a median cumulative ANT dose comparable to our study. These authors used published reference values for adults derived from a population older or equal to 50 years [29]. The applicability of these cut-off reference NTproBNP values to our adolescent and young adult population may be debatable. In the present study, normal values of NTproBNP were different for females $(<105 \mathrm{pg} / \mathrm{mL})$ and males $(<75 \mathrm{pg} / \mathrm{mL})$ (below 97.5 th percentile from our controls).

Similarly as in some studies, NTproBNP levels were significantly related to cumulative ANT dose in our survivors, yet these concentrations were not correlated with LVEF and DT [23,26].

Given the young age of our survivor population and the rarity of other diseases in young patients, the increased values of NTproBNP found in survivors may provide an useful information on late ANT subclinical cardiotoxicity.

\section{Conclusions}

Higher levels of NTproBNP detected in childhood leukemia survivors after low anthracycline cumulative doses might reflect an initial stage of ANT cardiotoxicity before the development of echocardiographic abnormalities. Although the current studies support
NTproBNP as one of the best available biochemical markers of late anthracycline cardiotoxicity, a possible strategy toward further improvement and combination with other cardiac biomarkers and novel echocardiographic methods should be explored in additional studies.

\section{Abbreviations}

A: Peak flow velocity of late filling; Am: Late diastolic myocardial velocity; ANT Group: patients previously treated with anthracyclines; DT: Deceleration time; E: Peak flow velocity of early filling; Ea: Early diastolic annular velocity; EF: Ejection fraction; Em: Early diastolic myocardial velocity; IVRT: Left ventricular isovolumetric relaxation time; LA: Left atrium dimension; LV: Left ventricular; LVEDD: Left ventricular end-diastolic diameter; LVESD: Left ventricular end-systolic diameter; MUGA: Multi Gated Acquisition Scan; nonANT: Patients previously treated without anthracyclines; NTproBNP: $\mathrm{N}$-terminal pro-brain natriuretic peptide; RV: Right ventricular dimension; Sm: Systolic velocity at myocardial segments; TDI: Tissue Doppler imaging.

Competing interests

The authors indicated no potential conflicts of interest.

\section{Authors' contributions}

Conception and design: BM Collection and assembly of data: DU, IS Data analysis and interpretation: ER, PS Manuscript writing: BM, DU Final approval of manuscript: All authors.

\section{Acknowledgments}

The authors thank Katarina Ondrejkovicova, M.Sc., for assistance with the analyses of biomarkers. This work was supported by a grant of the Scientific Agency of the Ministry of Health 2007/42-UK-18, Slovak Republic.

\section{Author details}

${ }^{1}$ Institute of Pathological Physiology, School of Medicine, Comenius University, Sasinkova 4, 811 08, Bratislava, Slovak Republic. ${ }^{2}$ Department of Neonatology, Faculty Hospital, Nove Zamky, Slovak Republic. ${ }^{3}$ Department of Cardiology, Slovak Medical University and National Institute of Cardiovascular Diseases, Bratislava, Slovak Republic.

Received: 18 August 2012 Accepted: 3 October 2012

Published: 11 October 2012

\section{References}

1. Mulrooney DA, Yeazel MW, Kawashima T, Mertens AC, Mitby P, Stovall M, Donaldson SS, Green DM, Sklar CA, Robison LL, Leisenring WM: Cardiac outcomes in a cohort of adult survivors of childhood and adolescent cancer: retrospective analysis of the Childhood Cancer Survivor Study cohort. BMJ 2009, 339:b4606.

2. Lipshultz SE, Miller TL, Scully RE, Lipsitz SR, Rifai N, Silverman LB, Colan SD, Neuberg DS, Dahlberg SE, Henkel JM, Asselin BL, Athale UH, Clavell LA, Laverdière C, Michon B, Schorin MA, Sallan SE: Changes in cardiac biomarkers during doxorubicin treatment of pediatric patients with high-risk acute lymphoblastic leukemia: associations with long-term echocardiographic outcomes. J Clin Oncol 2012, 30(10):1042-1049.

3. Paulides M, Kremers A, Stöhr W, Bielack S, Jürgens H, Treuner J, Beck JD, Langer T, German Late Effects Working Group in the Society of Pediatric Oncology and Haematology (GPOH): Prospective longitudinal evaluation of doxorubicin-induced cardiomyopathy in sarcoma patients: a report of the Late Effects Surveillance System (LESS). Pediatr Blood Cancer 2006, 46:489-495

4. Mladosievicova B, Foltinova A, Luptak I, Petrasova H, Hulin I: Frequency-domain analysis of the QRS complex after treatment of childhood cancer with anthracycline cytostatics. Pediatr Cardiol 2001 22:478-482.

5. Kremer LC, van Dalen EC, Offringa M, Ottenkamp J, Voute PA: Anthracycline-induced clinical heart failure in a cohort of 607 children: long-term follow-up study. J Clin Oncol 2001, 19:191-196.

6. Salzer WL, Devidas M, Carroll WL, Winick N, Pullen J, Hunger SP, Camitta BA: Long-term results of the Pediatric Ooncology Group studies for childhood acute lymphoblastic leukemia 1984-2001: a report from the Children's Oncology Group. Leukemia 2010, 24(2):355-370. 
7. Pein F, Sakiroglu O, Dahan M, Lebidois J, Merlet P, Shamsaldin A, Villain E, de Vathaire F, Sidi D, Hartmann O: Cardiac abnormalities 15 years and more after adriamycin therapy in 229 childhood survivors of a solid tumour at the Institute Gustave Roussy. Br J Cancer 2004, 91(1):37-44.

8. Oeffinger KC, Mertens AC, Sklar CA, Kawashima T, Hudson MM, Meadows AT, Friedman DL, Marina N, Hobbie W, Kadan-Lottick NS, Schwartz CL, Leisenring W, Robison LL: Childhood Cancer Survivor Study. Chronic health conditions in adult survivors of childhood cancer. N Engl J Med 2006, 355:1572-1582.

9. Lipshultz SE, Colan SD, Gelber RD, Perez-Atayde AR, Sallan SE, Sanders SP: Late cardiac effects of doxorubicin therapy for acute lymphoblastic leukemia in childhood. N Engl J Med 1991, 1324:808-815.

10. Sawaya H, Sebag IA, Plana JC, Januzzi JL, Ky B, Tan TC, Cohen V, Banchs J, Carver JR, Wiegers SE, Martin RP, Picard MH, Gerszten RE, Halpern EF, Passeri J, Kuter I, Scherrer-Crosbie M: Assessment of echocardiography and biomarkers for the extended prediction of cardiotoxicity in patients treated with anthracyclines, taxanes and trastuzumab. Circ Cardiovasc Imaging 2012, 5(5):596-603.

11. Stoodley PW, Richards DA, Hui R, Boyd A, Harnett PR, Meikle SR, Clarke J, Thomas $\mathrm{L}$ : Two-dimensional myocardial strain imaging detects changes in left ventricular systolic function immediately after anthracycline chemotherapy. Eur J Echocardiogr 2011, 12(12):945-952.

12. Lang RM, Bierig M, Devereux RB, Flachskampf FA, Foster E, Pellikka PA, Picard MH, Roman MJ, Seward J, Shanewise JS, Solomon SD, Spencer KT, Sutton MS, Stewart WJ: Recommendations for chamber quantification: a report from the American Society of Echocardiography's Guidelines and Standards Committee and the Chamber Quantification Writing Group, developed in conjunction with the European Association of Echocardiography, a branch of the European Society of Cardiology. J Am Soc Echocardiogr 2005, 18(12):1440-1463.

13. Roziakova L, Bojtarova E, Mistrik M, Dubrava J, Gergel J, Lenkova N, Mladosievicova B: Serial measurements of cardiac biomarkers in patients after allogeneic hematopoietic stem cell transplantation. J Exp Clin Cancer Res 2012, 31:13-23.

14. Januzzi JL, Van Kimmenade R, Lainchbury J, Bayes-Genis A, Ordonez-Llanos J, Santalo-Bel M, Pinto YM, Richards M: NT-proBNP testing for diagnosis and short-term prognosis in acute destabilized heart failure: an international pooled analysis of 1256 patients: the International Collaborative of NT-proBNP Study. Eur Heart J 2006, 27:330-337.

15. Sandri MT, Salvatici M, Cardinale D, Zorzino L, Passerini $R$, Lentati $P$, Leon $M$, Civelli M, Martinelli G, Cipolla CM: N-terminal pro-B-type natriuretic peptide after high-dose chemotherapy: a marker predictive of cardiac dysfunction? Clin Chem 2005, 51(8):1405-1410.

16. Dolci A, Dominici R, Cardinale D, Sandri MT, Panteghini M: Biochemical markers for prediction of chemotherapy-induced cardiotoxicity: systematic review of the literature and recommendations for use. Am J Clin Pathol 2008, 130:688-695.

17. Cardinale D, Sandri MT: Role of biomarkers in chemotherapy-induced cardiotoxicity. Prog Cardiovasc Dis 2010, 53(2):121-129.

18. Bryant J, Picot J, Baxter L, Levitt G, Sullivan I, Clegg A: Use of cardiac markers to assess the toxic effects of anthracyclines given to children with cancer: a systematic review. Eur J Cancer 2007, 43(13):1959-1966.

19. Daugaard $G$, Lassen $U$, Bie P, Pedersen EB, Jensen KT, Abildgaard U, Hesse B, Kjaer A: Natriuretic peptides in the monitoring of anthracycline induced reduction in left ventricular ejection fraction. Eur J Heart Fail. 2005, 7:87-93.

20. Soker M, Kervancioglu M: Plasma concentrations of NT-pro-BNP and cardiac troponin-I in relation to doxorubicin-induced cardiomyopathy and cardiac function in childhood malignancy. Saudi Med J. 2005, 26:1197-1202.

21. Koh E, Nakamura T, Takahashi H: Troponin-T and brain natriuretic peptide as predictors for adriamycin-induced cardiomyopathy in rats. Circ J 2004, 68:163-167.

22. Nousiainen T, Vanninen E, Jantunen E, Puustinen J, Remes J, Rantala A, Vuolteenaho O, Hartikainen J: Natriuretic peptides during the development of doxorubicin-induced left ventricular diastolic dysfunction. J Intern Med. 2002, 251:228-234.

23. Horacek JM, Vasatova M, Tichy M, Pudil R, Jebavy L, Maly J: The use of cardiac biomarkers in detection of cardiotoxicity associated with conventional and high-dose chemotherapy for acute leukemia. Exp Oncol 2010, 32(2):97-99.
24. Kozlowski AM, Constine LS, Proukou C, Lipsitz SR, Miller TL, Vermilion RP, Rifai N: Accelerated atherosclerosis contributes to elevated global risk for premature symptomatic cardiovascular disease in survivors of childhood cancer. Proc Am Soc Clin Oncol 2003, abstr 3203.

25. Germanakis I, Kalmanti M, Parthenakis F, Nikitovic D, Stiakaki E, Patrianakos A, Vardas PE: Correlation of plasma N-terminal probrain natriuretic peptide levels with left ventricle mass in children treated with anthracyclines. Int J Cardiol 2006, 108:212-215.

26. Mavinkurve-Groothius AM, Groot-Loonen J, Bellersen L, Pourier MS, Feuth T, Bökkerink JP, Hoogerbrugge PM, Kapusta L: Abnormal NT-pro-BNP levels in asymptomatic long-term survivors of childhood cancer tretated with anthracyclines. Pediatr Blood Cancer 2009, 52(5):631-636.

27. Urbanova D, Urban L, Simkova I, Danova K, Mikuskova E, Mladosievicova B: Long-term cardiac effects of treatment for childhood leukemia. Neoplasma 2010, 57(2):179-183.

28. Lipshultz SE, Landy DC, Lopez-Mitnik G, Lipsitz SR, Hinkle AS, Constine LS, French CA, Rovitelli AM, Proukou C, Adams MJ, Miller TL: Cardiovascular status of childhood cancer survivors exposed and unexposed to cardiotoxic therapy. J Clin Oncol 2012, 30(10):1050-1057.

29. Raymond I, Groenning BA, Hildebrandt PR, Nilsson JC, Baumann M, Trawinski J, Pedersen F: The influence of age, sex and other variables on the plasma level of $\mathrm{N}$-terminal pro brain natriuretic peptide in a large sample of the general population. Heart 2003, 89(7):745-751.

doi:10.1186/1756-9966-31-86

Cite this article as: Mladosievicova et al:: Role of NT-proBNP in detection of myocardial damage in childhood leukemia survivors treated with and without anthracyclines. Journal of Experimental \& Clinical Cancer Research $201231: 86$

\section{Submit your next manuscript to BioMed Central and take full advantage of:}

- Convenient online submission

- Thorough peer review

- No space constraints or color figure charges

- Immediate publication on acceptance

- Inclusion in PubMed, CAS, Scopus and Google Scholar

- Research which is freely available for redistribution 